\title{
O que é a vida segundo as Cortes Constitucionais do novo constitucionalismo latino-americano?
}

\section{Siddharta Legale}

Professor de Direito Constitucional da UFJF. Doutorando em Direito Internacional pela UERJ. Mestre em Direito Constitucional e Bacharel pela UFF.

\section{Resumo}

$\mathrm{O}$ artigo aborda o direito à vida no novo constitucionalismo latino-americano. Ele destaca as diferenças entre a jurisprudência dos Tribunais Constitucionais do Brasil e Colômbia de um lado, face a jurisprudência do Equador e Bolívia de outro. As Cortes Constitucionais brasileira e colombiana enfatizam a dignidade humana como direito, enquanto a equatoriana e a boliviana escolhem um conceito original: o "bem viver", chamado "bién vivir" em espanhol ou "sumak kawsay" em dialeto indígena.

\section{Palavras-chave}

Neoconstitucionalismo; Novo constitucionalismo latino-americano e direito à vida.

\section{What is life after new Latin-American constitutionalism Constitutional Courts interpretation?}

\begin{abstract}
The paper approaches the right to life at new Latin-American constitutionalism. It highlights the different approaches among the caselaw of Constitutional Courts of Brazil, Colombia, Ecuador and Bolivia. The Brazilian and Colombian Courts emphasize the human dignity as a right, while Ecuadorian and Bolivian choose one original concept: the "good life", called "bién viver" in Spanish or "sumak kawsay" in indigenous dialect.
\end{abstract}

\section{Keywords}

New constitutionalism; Latin American constitutionalism and right to life. 


\section{Sumário}

1. Aspectos gerais; 2. O novo constitucionalismo latino-americano: um ensaio sobre seus marcos; 3. O direito à vida na jurisprudência das Cortes Constitucionais: entre a dignidade da pessoa humana e o bem viver; 4 . Apontamentos finais.

\section{Aspectos Gerais}

A vida, como um direito humano fundamental, será apresentada a partir da jurisprudência da Corte Constitucional da Colômbia e do Supremo Tribunal Federal, bem como da Corte Constitucional do Equador e do Tribunal Plurinacional da Bolívia. Em linhas gerais, o ponto de partida para esse esforço de direito comparado será o contraste entre duas perspectivas de respostas à pergunta: o que é a vida para o direito?

A primeira perspectiva adota premissas antropocêntricas ocidentalizadas de um típico Estado Social e Democrático Direito, que compreende o direito à vida a partir da noção de dignidade da pessoa humana. É o que se observa na visão individualista do STF (ADPF 54 sobre anencefalia e ADI 3510 sobre a pesquisa com células-tronco) e da visão social da Corte da Colômbia (Sentença C-355/06 e T-388/09 sobre o aborto, Sentença C239/97 e Sentença T-970/14 sobre eutanásia).

A segunda discorre sobre uma visão biocêntrica ou geocêntrica na qual o ser humano deve viver em harmonia com a mãe terra, a "Pachamama", típicas de um Estado Plurinacional de Direito. Essa é a visão que pode ser encontrada na jurisprudência da Corte Constitucional do Equador na decisão relativa ao genocídio (caso 0072-14-CN, o chamado caso Waorani) ou na decisão do Tribunal Constitucional Plurinacional da Bolívia que trata do aborto (Sentença Constitucional Plurinacional n. 0206/2014)

A escolha das Cortes Constitucionais da Colômbia, Brasil, Bolívia e Equador não se deu de forma aleatória. A seleção teve como critério o pertencimento das Cortes ao "novo constitucionalismo latino-americano" ${ }^{\prime 1}$, retratando que, mesmo no interior do movimento,

\footnotetext{
1 Para uma visão geral do fenômeno, Cf. por ex., DALMAU, Rubens Martinez.¿se pude hablar de un nuevo constitucionalismo latinoamericano como corriente doctrinal sistematizada? Trabalho apresentado no Congresso Mundial de Direito Constitucional, 2010. Disponível em: <http://www.juridicas.unam.mx/wccl/ponencias/13/245.pdf> Do mesmo autor, V. Asembleas constituintes e novo constitucionalismo em América Latina. Tempo exterior: Revista de análise e estudos internacionais. N. 17, 2008. Disponível em: <http://www.igadi.org/te/pdf/te_se17/te29_17_005_ruben_martinez_dalmau.pdf> OLIVEIRA, Fabio Correa Souza de e GOMES, Camila Beatriz Sardo. O Novo Constitucionalismo Latino-americano. In: CARVALHO, Flávia Martins de e VIEIRA, José Ribas. Desafios da Constituição - Democracia e Estado no século XXI. Rio de Janeiro, UFRJ, 2011, p. 333 e ss.
} 
há diferentes graus de adesão ao pluralismo. Nos países do novo constitucionalismo latino americano do primeiro ciclo (Brasil e Colômbia), há uma afinidade maior com a noção de dignidade da pessoa humana. Por outro lado, nos países do terceiro ciclo do novo constitucionalismo latino-americano (Equador e Bolívia), há uma ênfase maior no "bem viver", sumak kawsay ${ }^{2}$.

Para abordar a questão "o que é a vida segundo as Cortes do novo constitucionalismo latino-americano?", percorremos o seguinte roteiro: (i) a primeira parte conceituará o novo constitucionalismo, diferenciando do neoconstitucionalismo, mas inspirado neste, procurando estabelecer os marcos desse importante movimento em curso; e (ii) o direito à vida na jurisprudência das Cortes que compõem esse movimento, apresentando as diferentes abordagens a partir da dignidade da pessoa humana e do bem viver. Vejamos.

\section{O novo constitucionalismo latino-americano: um ensaio}

\section{sobre seus marcos}

O neoconstitucionalismo não se confunde com o novo constitucionalismo latinoamericano. Destacaremos, inicialmente, os marcos do neoconstitucionalismo para, em seguida, tentar descrever e propor marcos próprios ao novo constitucionalismo latinoamericano, como uma forma de evidenciar semelhanças e diferenças entre ambos.

$\mathrm{Na}$ falta de um nome mais preciso, convencionou-se chamar de neoconstitucionalismo, o movimento ou os movimentos que, em linhas gerais, possuem os seguintes marcos na consagrada síntese do prof. Luís Roberto Barroso: (i) histórico - o pós-guerra; (ii) filosófico - o pós-positivismo; e (iii) o teórico - a força normativa da Constituição, a nova interpretação constitucional e a expansão da jurisdição constitucional; e, por isso, vivencia o que se chama de constitucionalização do direito ${ }^{3}$.

\footnotetext{
2 Destaque-se, de plano, que será abordado o bem viver dentro da cosmologia indígena dos povos da América Latina. Não se pretende abordar a importante e clássica questão filosófica da diferença entre a vida boa e de viver bem. Sobre a questão filosófica, Cf. DWORKIN, Ronald. O que é uma vida boa?. Trad. Emilio Peluso Neder Meyer e Alonso Reis Freire Rev. direito GV [online]. 2011, vol.7, n.2, pp. 607-616.

${ }^{3}$ Sobre o tema, Cf. BARROSO, Luís Roberto. Neoconstitucionalismo e constitucionalização do direito (O triunfo tardio do direito constitucional no Brasil). In: Cláudio Pereira de Souza Neto e Daniel Sarmento (Coord. A Constitucionalização do Direito: Fundamentos teóricos e aplicações específicas. Rio de Janeiro: Lumen Juris, 2007, p. 203 e ss. Para uma visão crítica do fenômeno, Cf. DIMOULIS, Dimitri. Neoconstitucionalismo e moralismo jurídico. In: SARMENTO, Daniel (Org.). Filosofia e teoria constitucional contemporânea. Rio de Janeiro: Lumen Juris, 2009, p..219. Sobre a crítica ao pendor judicialista, à preferência pro princípios e a panconstitucionalização, Cf. SARMENTO, Daniel. O Neoconstitucionalismo no Brasil: Riscos e possibilidades. In: Filosofia e teoria constitucional 
As Constituições europeias do pós-guerra, como a alemã, italiana, espanhola e portuguesa, passaram a ser mais comumente tratadas e retratadas, do ângulo formal, como o centro ou cume do ordenamento jurídico que serviria de parâmetro para as demais normas, enquanto, do ponto de vista material, passaram a ser Cartas principiológicas, destinadas a conformar a realidade. É verdade que desde o século XIX difundiu-se o paradigma de a Constituição ser o documento superior da ordem jurídica, notadamente, por influência do constitucionalismo norte-americano, com o precedente Marbury vs. Madison. Defende-se que a intensidade e qualidade desse controle teria se aprofundado após a Segunda Guerra Mundial, consolidando-se uma força normativa de algumas Constituições por meio de um amplo processo de constitucionalização do direito que cuidou de reforçar tal normatividade ${ }^{4}$.

A nova interpretação constitucional ampliou ainda mais a força normativa da Constituição, bem como de permitir uma contextualização e atualização constante. Trata-

contemporânea. Rio de Janeiro: Lumen Juris, 2009, p.132 e ss. Sobre a crítica democrática e metodológica à constitucionalização, Cf. SARMENTO, Daniel. Ubiqüidade constitucional: os dois lados da moeda. In: Cláudio Pereira de Souza Neto e Daniel Sarmento, A Constitucionalização do Direito. Rio de Janeiro: Lumen Juris, 2007, p. 113-48. CARBONELL, Miguel. El neoconstitucionalismo en su laberinto. In: CARBONELL, Miguel.(Org.) Teoría Del neoconstitucionalismo. Editorial trotta, instituti de investigaciones jurídicas UNAM, sem data, p.1. O autor já havia tratado da mesma ideia anteriormente; CARBONELL, Miguel. Prólogo: Nuevos tiempos para el constitucionalismo. In: CARBONELL, Miguel. Neoconstitucionalismo(s) Madrid: Editorial Trota, 2003; SOUZA NETO, Cláudio Pereira de. $O$ dilema constitucional contemporâneo entre o neoconstitucionalismo econômico e $O$ constitucionalismo democrático. In: COUTINHO, Jacinto Nelson de Miranda; LIMA, Martonio Mont'alverne Barreto. Diálogos constitucionais: Direito, Neoliberalismo e desenvolvimento em países periféricos. Rio de Janeiro: Renovar, 2006.

${ }^{4}$ A constitucionalização do direito pode ser apresentada em quatro espécies: elevação (ou inclusão), transformação (ou releitura) e juridicização. A constitucionalização inclusão significa que temas que tradicionalmente eram tratados no plano infraconstitucional passaram a integrar o texto constitucional. A constitucionalização transformação ou releitura opera uma influência ou filtragem à luz da Constituição, em especial das noções de direitos fundamentais e democracia. Opera-se, com isso, uma releitura do direito por meio da valorização dos princípios dotados de normatividade. Defende-se um pós-positivismo por meio de uma verdadeira leitura moral do Direito e uma positivação e normatividade dos princípios que Ricardo Lobo Torres bem denominou de "virada kantiana". Por fim, a constitucionalização juridicização significa que o conteúdo da Constituição passou a ser visto também no desenvolvimento dos precedentes das Cortes. A jurisprudência assumiu um papel de destaque. Há quem fale inclusive em uma "jurisprudencialização do direito", ou seja, a jurisprudência como fonte criadora do direito. O outro lado da moeda é a possibilidade de "correção legislativa da jurisprudência". Cf. FAVOREU, Louis. La constitutionnalisation du droit. In: Jean-Bernard Auby et al., L'unité du droit. Paris: Economica, 1996, p. 36-8 BARROSO, Luís Roberto. Curso de Direito Constitucional Contemporâneo. Rio de Janeiro: Saraiva, 2009, p. 243-266; e BARROSO, Luís Roberto. Neoconstitucionalismo e a constitucionalização do Direito (O triunfo tardio do direito constitucional no Brasil). In: SOUZA NETO, Cláudio Pereira de; SARMENTO, Daniel (orgs.). A Constitucionalização do Direito. Fundamentos Teóricos e Aplicações Específicas. p. 203-250. SILVA, Virgílio Afonso. A Constitucionalização do direito. São Paulo: Malheiros, 2008, p. 46-7. SOUZA NETO, Cláudio Pereira de e MENDONÇA, José Vicente Santos de. Fundamentalização e fundamentalismo na interpretação do princípio constitucional da livre iniciativa. In: SOUZA NETO, Cláudio Pereira de e SARMENTO, Daniel (Orgs.). A Constitucionalização do Direito. Rio de Janeiro: Lumen Juris, 2007, p. 709 e ss. 
se de uma proposta que coloca, ao lado dos elementos ou métodos clássicos de interpretação (gramatical, sistemático, histórico e teleológico), novos princípios específicos de interpretação constitucional, como o da unidade da Constituição, máxima efetividade da Constituição, proporcionalidade e etc. Opera-se não só com a subsunção, mas também, quando cabível, com a ponderação de interesses como forma de equacionar a tensões entre princípios que colidem no caso concreto, mas permanecem igualmente válidos ${ }^{5}$.

A expansão da jurisdição constitucional, por sua vez, erigiu-se em verdadeira garantia institucional à proteção do conteúdo da Constituição ${ }^{6}$. O controle jurisdicional de constitucionalidade das leis foi amplamente difundido no mundo e até países que adotavam um modelo de separação rígida dos poderes passaram a prever fórmulas análogas. Houve no período uma intensa judicialização da vida e da política ${ }^{7}$. Temas que tradicionalmente não ingressavam no Judiciário são discutidos nessa seara e, ainda, o Judiciário adota um papel mais ativo. Esse ativismo apoia-se na concretização de princípios jurídicos indeterminados, de direitos fundamentais e em uma interpretação criativa de normas constitucionais. O Tribunal constitucional é convocado a tratar a Constituição como norma, o que conduziu a inúmeros debates e controvérsias sobre a legitimidade democrática do Poder Judiciário e o seu papel contramajoritário ${ }^{8}$.

Destaque-se, por fim, que, embora existam diferenças entre o neoconstitucionalismo e novo constitucionalismo latino-americano, as diferenças têm sido exacerbadas no Brasil pela doutrina. Vincadas as diferenças, os autores acabam por minimizar ou ignorar os pontos de aproximação ou convergência. Em alguns países, emprega-se até mesmo a expressão neoconstitucionalismo latino-americano para

\footnotetext{
${ }^{5}$ Para mais detalhes sobre a interpretação constitucional no neoconstitucionalismo, Cf. BARROSO, Luis Roberto. Interpretação e Aplicação da Constituição. 7ạ. São Paulo: Saraiva, 2010. BARCELOS, Ana Paula. Ponderação, racionalidade e atividade jurisdicional. Rio de Janeiro: Renovar, 2006. PEREIRA, Jane Reis Gonçalves. Interpretação e direitos fundamentais. Rio de Janeiro: Renovar, 2006. SARMENTO, Daniel. Os princípios constitucionais e a ponderação de bens. In: LOBO TORRES, Ricardo (Org.). Teoria dos direitos fundamentais. Rio de Janeiro: Renovar, 1999.

${ }^{6}$ Existe um debate clássico entre quem deveria ser o guardião da Constituição em que Kelsen defendeu que deveria ser um tribunal constitucional, enquanto Carl Schmitt o Chefe do Executivo. Cf. KELSEN, Hans. Jurisdição constitucional. São Paulo: Martins Fontes, 2003.

7 VIANNA, Luiz Werneck; CARVALHO, Maria Alice Resende de. Manoel Palacios Cunha Melo; BURGOS, Marcelo Baumann. A judicialização da política e das relações sociais no Brasil. Rio de Janeiro: Revan, 1999.

${ }^{8}$ Existem diversas posições sobre a compatibilidade entre jurisdição constitucional e a democracia. Pela compatibilidade parcial, Cf. BICKEL, Alexander. The last dangerous branch. Yale University Press, p. 1-33. Pela compatibilidade plena considerando uma jurisprudência dos valores, Cf. BACHOFF, Otto. Jueces y constitución. Madrid: Editorial civitas, 1987, p. 9- 69. Pela incompatibilidade, propondo inclusive a abolição da corte constitucional, Cf. TUSHNET, Mark. Taking the constitution away from the Courts. Princeton: Princeton University, 2000.
} 
designar o fenômeno. Inspirados nos marcos construídos para o neoconstitucionalismo, ensaiaremos a seguir propor marcos próprios para o novo constitucionalismo, facilitando a comparação entre ambos, procurando atribuir o devido peso às semelhanças e diferenças entre ambos.

O novo constitucionalismo latino-americano, por sua vez, como bem destaca o prof. Enzo Bello, decorre mais da atuação de movimentos sociais ${ }^{9}$ na América Latina do que de teorizações acabadas oriundas dos professores das universidades, como Alexy ou Dworkin. O nome atribuído também se deu na falta de um nome mais preciso, a despeito das crescentes reflexões e a produção teórica sobre esse movimento em curso. A seguir, propõe-se descrever e elaborar a partir dos seguintes marcos: histórico, filosófico e sociológico ${ }^{10}$.

O marco histórico aponta para as transformações decorrentes dos movimentos sociais que culminaram na aprovação de novas Constituições do Brasil de 1988, a Colômbia de $1991^{11}$, Venezuela de $1999^{12}$, Equador de 2008 e Bolívia de $2009^{13}$. Não desejamos abordar os detalhes histórico-políticos do processo constituinte de cada uma dessas Constituições, que são analíticas, dirigentes, pautadas pelo modelo de democracia participativa e pela constitucionalização dos direitos das populações originárias, em

${ }^{9}$ Sobre a emergência dos movimentos sociais e a construção da cidadania no período na América Latina, ora centrado em carências sociais (ex: sem terra e sem teto), ora em identidades étnicas (ex: Bolívia e Equador), Cf. BELLO, Enzo. Política, cidadania e direitos sociais: um contraponto entre os modelos clássicos e a trajetória da América Latina. Dissertação de Mestrado pela PUC-RJ, 2007, p. 140 e ss. Do mesmo autor, vale conferir as reflexões a partir do pensamento de Gramsci para a América Latina. V. BELLO, Enzo. A cidadania na luta política dos movimentos sociais urbanos. Caxias do Sul: Educs, 2013, p. 167 e ss.

10 Inspiramo-nos para construção dos marcos do novo constitucionalismo no conhecido e original texto do professor Luís Roberto Barroso. V. BARROSO, Luís Roberto. Neoconstitucionalismo e constitucionalização do Direito. In: Temas de direito constitucional, t. IV. Rio de Janeiro: Renovar, 2009. Destacamos, porém, que "neo" e "novo constitucionalismo latino-americano" não se confundem. Ambos possuem teoria e prática, mas o primeiro é muito mais um movimento teórico com repercussões institucionais, enquanto o segundo um movimento social, como descrevemos a seguir. Por essa razão, destacamos o marco sociológico, como componente central do novo constitucionalismo. Para uma comparação breve e precisa entre ambos, Cf. FERNDANDES, Bernardo Gonçalves. A teoria da Constituição à luz dos movimentos do constitucionalismo (moderno), do neoconstitucionalismo (contemporâneo), do transconstitucionalismo e do constitucionalismo (latino-americano) plurinacional. In: MORAIS, José Luis Bolzan de; BARROS, Flaviane de Magalhães Barros. Novo Constitucionalismo latino-americano. Belo Horizonte: Arraes Editores, 2014, p. 37 e ss 11 Não ignoramos que existem controvérsias doutrinárias sobre o enquadramento do Brasil e da Colômbia no novo constitucionalismo. Apesar das características mais frágeis para o enquadramento desses países, entendemos que estão presentes, embora em menor grau. Optamos, por isso, por inseri-los no primeiro ciclo do movimento.

12 DALMAU, Rubens Martinez.PASTOR, Roberto Viciano. ¿Ganar o perder? La propuesta de reforma constitucional em Venezuela y el referendo de 2007. Disponível em: <http://www.ceps.es/webantigua/investigacion/informes/ptalsxxi/1-julio2008.pdf>

13 UPRIMNY, Rodrigo. Las transformaciones recientes em America Latina: tendências e desafios. Trabalho apresentado no Congresso Mundial de Direito Constitucional, 2010.Disponível em: <http://www.juridicas.unam.mx/wccl/ponencias/13/242.pdf> 
especial às indígenas, com atenção a sua participação em variadas instâncias de poder ${ }^{14}$. Para a finalidade do presente trabalho, basta dizer que há três ciclos: o primeiro ciclo pauta-se na descentralização do poder, sendo representado pelo Brasil e pela Colômbia; o segundo envolve o aprofundamento dos mecanismos de democracia participativa, com especial destaque para Venezuela; e o terceiro ciclo refere-se ao aprofundamento dos direitos das populações originárias e da construção do Estado Plurinacional, por exemplo, no Equador e na Bolívia ${ }^{15}$.

O marco filosófico apoia-se na reivindicação de um processo descolonizador, passível de ser descrito a partir da epistemologia do Sul ${ }^{16}$ ou da filosofia da libertação ${ }^{17}$. Em linhas gerais, ambas procuram contestar uma visão homogeneizante da modernidade ocidental-europeia, propondo uma emancipação a partir de um "Sul" metafórico. A metáfora simboliza a necessidade de inclusão da cosmovisão e o conhecimento das populações originárias. O "Sul", portanto, não é meramente geográfico. Significa uma espécie de reinvindicação por maior diversidade na produção do conhecimento, que não se paute de forma exclusiva na produção do "Norte". Trata-se de uma manifestação contra as formas de colonialismo ou neoconstitucionalismo nas dimensões política, cultural, econômica etc ${ }^{18}$. Por isso, libertar a América Latina das formas de colonialismo (ou neocolonialismo) pressupõe valorizar a produção filosófica e cultural da região é um objetivo central do movimento.

Representativa dessa característica é a positivação de muitos conceitos decorrentes de visões de mundo (ou cosmologias) típicas das populações originárias, como os Aimarás. É emblemática, nesse sentido, a inclusão de termos, como suma qmanã, sumak Kawsay ou bien vivir nas Constituições da Bolívia e Equador. O "bem viver" desempenha uma função análoga a da dignidade humana ${ }^{19}$ em Constituições ocidentais,

14 GARGARELLA, Roberto. Latin American constitutionalism: the engine room of Constitution - 18082010. Oxford University Press, 2013, p. 181 e ss.

15 WOLKMER, Antonio Carlos e FAGUNDES, Lucas Machado. Tendências contemporâneas do constitucionalismo latino-americano: Estado plurinacional e pluralismo jurídico. Pensar - Revista de Ciências jurídicas v. 16, n. 2 de jul./dez., 2011.

16 SANTOS, Boaventura de Sousa e MENESES, Maria Paula. Introdução. In: Epistemologias do Sul. Coimbra: Almedina, 2010, p.9 e ss.

17 DUSSEL, Enrique. Meditações anto-cartesianas sobre a origem do anti-discurso filosófico da modernidade. In: SANTOS, Boaventura de Sousa e MENESES, Maria Paula. (Orgs.) Epistemologias do Sul. Coimbra: Almedina, 2010, p. 305 e ss. DUSSEL, Enrique. Filosofía de la liberación. p. 54-91. Disponível em:<http://www.olimon.org/uan/liberacion.pdf.>

18 Não desejamos adentrar na filigrana das diferenças entre colonialismo e colonialidade. Cf. QUIJANO, Anibal. Colonialidade do poder e classificação social. In: SANTOS, Boaventura de Sousa e Meneses, Maria Paula. (Orgs.) Epistemologias do Sul. Coimbra: Almedina, 2010, p. 73 e ss.

19 SOUSA, Adriano Corrêa. O novo constitucionalismo latino-americano: um estudo comparado entre o bem-viver e a dignidade da pessoa humana nas culturas jurídico-constitucionais da Bolívia e do 
como na brasileira (art. 1으. III) ${ }^{20}$. A diferença, porém, é que o bem viver das Constituições da Bolívia (preâmbulo e art. 8으, I) e Equador (preâmbulo arts. 3으, 14 e 275), por exemplo, consubstanciam uma cosmologia biocêntrica ou geocêntrica que rompe com o antropocentrismo, ao defender a harmonia entre o homem e a natureza, a mãe terra (pachamama), que acaba por incluir a própria natureza como sujeito de direitos, tal como se dá no art. 71 da Constituição do Equador. ${ }^{21-22-23}$ Essa diferença entre o bem viver e a dignidade da pessoa humana ficará mais evidente, ao apresentarmos mais adiante a jurisprudência em especial do Tribunal Plurinacional da Bolívia, notadamente no caso em que se debate a constitucionalidade do aborto, conforme veremos mais adiante.

O marco sociológico, por fim, destaca o fato de o novo constitucionalismo resultar da dinâmica dos movimentos sociais na América Latina em defesa de um maior pluralismo cultural, econômico, social como uma forma de que o Estado seja plurinacional ${ }^{24}$ e não de uma construção teórico-dogmática monocultural acabada. Há quem afirme que o Brasil sob a vigência da Constituição de 1988 é um Estado pluriétnico ${ }^{25}$, enquanto a Bolívia e Equador com as Constituições de 2008 e 2009 seriam Estados plurinacionais ${ }^{26}$. A justificativa é o maior empoderamento jurídico e político das populações originárias bolivianas e equatoriana em relação à brasileira, representada, por exemplo, na eleição do Primeiro Presidente indígena no Equador, Evo Morales, ou na obrigatoriedade de que dois magistrados no Tribunal Plurinacional da Bolívia sejam de origem indígena ou campesina, como é o caso do seu recente Presidente Efren Choque Capuma.

Embora existam diferenças de graus entre os processos de constitucionalização e efetivação dos direitos das populações originárias, isso não parece suficiente para excluir

Brasil. Disponível em:

http://www.ppgdc.uff.br/index.php?option=com_content\&view=article\&id=7\&ltemid=15 >

20 Para um excelente e mais abrangente estudo de direito comparado, confira-se: BARROSO, Luís Roberto. A dignidade humana no direito constitucional contemporâneo: a construção de um conceito jurídico à luz da jurisprudência mundial. Belo Horizonte: Editora Fórum, 2013.

${ }^{21}$ SANTOS, Boaventura de Sousa. Para além do pensamento abissal: das linhas globais a uma ecologia de saberes. In: SANTOS, Boaventura de Sousa; MENESES, Maria Paula Epistemologias do sul. 2a. ed. Coimbra: Almedina, 2010. Cap. 1, p. 23-71.

22 DUSSEL, Enrique. Meditações anti-cartesianas sobre a origem do anti-discurso filosófico da modernidade. In: SANTOS, Boaventura de Sousa; MENESES, Maria Paula Epistemologias do sul. 2ª. ed. Coimbra: Almedina, 2010. Cap. 10, p. 307-357.

23 ZAFFARONI, Eugenio Raúl. La Pachamama y el humano. Buenos Aires: Ediciones Madres de Plaza de Mayo, 2012.

${ }^{24}$ WOLKMER, Antonio Carlos. Pluralismo e crítica do constitucionalismo na América Latina. Anais do IX Simpósio Nacional de Direito Constitucional da ABDConst, Curitiba, 2010. Disponivel em: <http://www.abdconst.com.br/revista3/antoniowolkmer.pdf>. Acesso em: 14 Janeiro 2012.

25 DUPRAT, Débora. Estado pluriétnico. Disponível em: < http://6ccr.pgr.mpf.mp.br/documentos-epublicacoes/artigos/docs_artigos/estado_plurietnico.pdf>

26 MAGALHÃES, José Luiz Quadros de. O Estado Plurinacional e direito internacional. Curitiba: Juruá, 2012. Do mesmo autor, Cf. O Estado Plurinacional na América Latina. Disponível em: <http://joseluizquadrodemagalhaes.blogstop/2010/09/41-Pluralidade-clima-conferencia.html> 
o Brasil e a Colômbia do movimento. Uma questão pontual em que essa diferença de grau se revela é que as terras indígenas, por exemplo, aqui no Brasil são bens da União sem representação política e não territórios indígenas com prerrogativas próprias. Um caso interessante, nesse sentido, envolve o julgamento do STF determinando a demarcação contínua e não em "queijo suíço", considerando a Constituição de 1988 como marco temporal de proteção das populações originárias e estabelecendo certos parâmetros, como no caso Raposa Serra do Sol ${ }^{27}$. O caso da Terra Limão Verde ilustra bem a questão ao definir a data da promulgação da Constituição de 1988, como marco para se verificar a existência ou não de esbulho de terras indígenas ${ }^{28}$.

De qualquer forma, qualquer tentativa de descrever tais conquistas, avanços, limitações e retrocessos de um fluxo de ideias e reivindicações de movimentos sociais em curso é sempre inevitavelmente incompleta, arriscada e prematura. Destaque-se, porém, que parece ser inegável que as Constituições do Equador e Bolívia impõem o dever mais robusto de o Estado promover e proteger o pluralismo e a plurinacionalidade, quando comparada com a brasileira. É possível ilustrar com um interessante caso no qual a Corte Constitucional do Equador em que se colocou o dever de a Universidade atender de forma intercultural às populações e nacionalidades Amawtay Wasi com a sua localização não apenas na capital, mas também nos territórios indígenas e respeitando e valorizando os seus saberes ${ }^{29}$.

Poderíamos ampliar a abordagem do "novo constitucionalismo latino-americano" tecendo mais detalhes. Foram pontuadas, porém, as características essenciais do fenômeno de forma sucinta apenas para justificar a escolha e explicitar o critério de comparabilidade entre as Cortes da Colômbia, Brasil, Equador e Bolívia ${ }^{30}$, como um modo

${ }^{27}$ STF, Pet 3388 / RR, Rel. Min. Carlos Britto, J. 19/03/2009, DJe 24-09-2009

${ }^{28}$ STF, ARE 803.462-AgR/MS*, Rel. Min. Min. Teori Zavascki

${ }^{29}$ Trata-se da Sentença 008-09-SAN-CC de 2009, conhecido como "Caso Amawtay Wasi"

30 Não desejamos realizar uma digressão sobre as escolhas metodológicas de forma mais técnica sobre a comparação. Para uma visão clássica, Cf. VERGOTTINI, Giusepe. Balance y perspectivas del dereho constitucional comparado. Disponível em: http://biblio.juridicas.unam.mx/libros/2/642/26.pdf>. CONSTANTINESCO, Leontin-Jean. Tratado de direito comparado: introdução ao direito comparado. Rio de Janeiro, 1998. Entre nós, Cf. SILVA, José Afonso da. Um pouco de Direito Constitucional Comparado. São Paulo: Malheiros, 2009. Para uma visão contemporânea, que destaca a importância assumida pela jurisprudência no trabalho das Cortes constitucionais. Cf. HIRSCHL, Ran. From comparative constitutional law to comparative constitutional Studies. International Journal Of Constitutional Law. Vol. 11, 2013, Editorial, p. 1-12. JACKSON, Vicki. Comparative constitutional law: Methodologies. In: The Oxford Handbook of Constitutional Law. Ed. Rosenfeld, Michel; SAJO, Andras. Oxford: Oxford University Press, 2013, p. 54-75. Também não desejamos adentrar na "batalha de metáforas" existente para descrever a comparação (empréstimos, transplantes, migrações ou engajamento). Por todos, Cf. PERJU, Vlad. Constitutional transplants, borrowing, and migrations. The Oxford Handbook of Constitutional Law. Ed. ROSENFELD, Michel; SAJO, Andras. Oxford: Oxford University Press, 2013, p. 1328/1349. 
de facilitar o levantamento de eventuais semelhanças e diferenças levantadas entre a jurisprudência dessas Cortes.

\section{0 direito à vida na jurisprudência das cortes constitucionais:}

\section{entre a dignidade da pessoa humana e o bem viver}

O que é a vida no Brasil, na Colômbia, no Equador ou na Bolívia? Há respostas diferentes? Adianta-se, que não se tem a pretensão de uma abordagem ampla ou filosófica sobre o conceito de vida ${ }^{31}$. Também não se pretende descrever o modo de vida ou qualidade de vida nesses países. Tampouco se pretende adentrar ou problematizar as ponderações efetuadas em casos extremos, "nos limites da vida", como em situações envolvendo aborto, eutanásia e clonagem ${ }^{32}$. A exposição circunscreve-se à abordagem jurídica, destacando elementos essenciais do conceito de vida presentes nas decisões das Cortes Constitucionais desses países. É claro que, embora essa abordagem tenha limitações, ela possui a virtude de evidenciar, em alguma medida, o papel representativo das Cortes e da jurisprudência, em especial do novo constitucionalismo latino-americano que acabam por exalar em suas decisões certos anseios sociais ${ }^{33}$.

No Brasil, em linhas gerais, o STF não adotou um conceito fechado de vida. Adotouse uma concepção gradualista, traçando marcos, como fecundação, nidação, formação do sistema neural e nascimento. Em cada um deles, o peso aumenta gradativamente. $\mathrm{Na}$ ADPF 54, sob a relatoria do Min. Marco Aurélio, a inviabilidade de vida extrauterina decorrente da anencefalia foi fundamental para que o STF decidisse sobre a possibilidade da interrupção da gestação. No HC 84025, anterior à ADPF 45, houve voto em sentido

31 Por todos, Cf. DWORKIN, Ronald. No domínio da vida. São Paulo Martins Fontes, 2009. Interessante flerte no plano do manual é apresentado pelo Professor José Afonso da Silva, quando define a vida como "Vida, no texto constitucional (arto5o caput), não será considerada apenas no seu sentido biológico de incessante auto-atividade funcional, peculiar à matéria orgânica, mas na sua acepção biográfica mais compreensiva. (...) Todo ser dotado de vida é indivíduo, isto é: algo que não pode dividir sob pena de deixar de ser. O Homem é um indivíduo, mas é mais que isto, é uma pessoa.". Cf. SILVA, José Afonso da. Curso de Direito constitucional Positivo. São Paulo: Malheiros, 2005, p. 197. Sobre o tema, vale conferir a premiada como melhor tese da área do direito pela CAPES em 2011. Cf. MARTEL, Letícia de Campos Velho. Direitos Fundamentais Indisponíveis: Limites e Padrões do Consentimento para a autolimitação do direito fundamental vida. Tese de Doutorado pela UERJ, 2010. Disponível em: <http://works.bepress.com/cgi/viewcontent.cgi?article=1006\&context=leticia_martel>

32 Sobre o tema, Cf. a coletânea, Cf. SARMENTO, Daniel; e PIOVESAN, Flávia (Coord.). Nos limites da vida: aborto, clonagem e eutanásia sob a perspectiva dos direitos humanos. Rio de Janeiro: Lumen Juris, 2007.

${ }^{33}$ Não desejamos desenvolver os desdobramentos e limitações da ideia de que as cortes possuem uma dimensão representativa. Para tanto, Cf. PEREIRA, Jane Reis Gonçalves. Representação democrática do Judiciário: reflexões preliminares sobre os riscos e dilemas de uma ideia em ascensão. Jurispoiesis (Rio de Janeiro), v. 17, 2014. 
semelhante, mas o caso não chegou a ser julgado ante o nascimento e perda do objeto do mesmo. Já na ADI $\mathbf{3 5 1 0}$ foi autorizada a pesquisa com células-tronco embrionárias, sendo precedida de uma audiência pública para decidir a questão ${ }^{34}$.

Na ADPF $54^{35}$ o Supremo Tribunal Federal entendeu que a anencefalia não pode ser tipificada, como aborto. Autorizou a interrupção de gestação de feto anencefálico com base na laicidade do Estado, na liberdade sexual e reprodutiva da mulher e na proteção da saúde e dignidade. Não chegou a constar na ementa, mas foi consignada pelos especialistas que se apresentaram na audiência pública e em alguns votos a inviabilidade da vida extrauterina e o fardo excessivo de impor a obrigatoriedade de a mulher carregar tal feto até o final da gestação, quando se sabe que o desfecho inevitavelmente será um natimorto.

A ADI $3510^{36}$ contra o art. 50 da Lei de Biossegurança foi julgada improcedente, mantendo-se, dentro de certos parâmetros, a autorização para a realização de pesquisas com células-tronco embrionárias. Entendeu-se que não havia violação ao direito à vida e que tal situação não se equiparava ao aborto, porque a Constituição não prevê expressamente quando começa a vida e a proteção dada ao embrião implantado não pode ser a mesma da proteção à vida em sentido biográfico. $O$ trecho da ementa adotou expressamente uma concepção gradualista da vida. Confira-se:

Mas as três realidades não se confundem: o embrião é o embrião, o feto é o feto e a pessoa humana é a pessoa humana. Donde não existir pessoa humana embrionária, mas embrião de pessoa humana. O embrião referido na Lei de Biossegurança ("in vitro" apenas) não é uma vida a caminho de outra vida virginalmente nova, porquanto lhe faltam possibilidades de ganhar as primeiras terminações nervosas, sem as quais o ser humano não tem factibilidade como projeto de vida autônoma e irrepetível. O Direito

${ }^{34}$ Sobre o tema, Cf. LEGALE, Siddharta; CAMARGO, Margarida Maria Lacombe; JOHANN, Rodrigo Fonseca. As audiências públicas no Supremo Tribunal Federal nos modelos Gilmar Mendes e Luiz Fux: a legitimação técnica e o papel do cientista no laboratório de precedentes. In: José Ribas Vieira, Vanice Regina Lírio do Valle e Gabriel Lima Marques. (Org.). Democracia e suas instituições. 1ed.Rio de Janeiro: IMOS, 2014, v. 1, p. 181-211. Disponível em: http://www.ufjf.br/siddharta_legale/files/2014/07/Margarida-Siddharta-Rodrigo-Asaudi\%C3\%AAncias-p\%C3\%BAblicas-no-STF-nos-modelos-Gilmar-e-Fux.pdf ${ }^{35}$ STF, ADPF 54/DF, Rel. Min. Marco Aurélio, J. 12.04.2012, DJe 29.04.2013. ESTADO - LAICIDADE. O Brasil é uma república laica, surgindo absolutamente neutro quanto às religiões. Considerações. FETO ANENCÉFALO - INTERRUPÇÃO DA GRAVIDEZ - MULHER - LIBERDADE SEXUAL E REPRODUTIVA - SAÚDE - DIGNIDADE - AUTODETERMINAÇÃO - DIREITOS FUNDAMENTAIS - CRIME INEXISTÊNCIA. Mostra-se inconstitucional interpretação de a interrupção da gravidez de feto anencéfalo ser conduta tipificada nos artigos 124, 126 e 128, incisos I e II, do Código Penal ${ }^{36}$ STF, ADI 3510, Rel. Min. Ayres Britto, J. 29.05.2008, DJe 27.05.2010 
infraconstitucional protege por modo variado cada etapa do desenvolvimento biológico do ser humano.

Considerou-se, ainda, que se deve realizar uma interpretação conforme às normas conformadoras do direito fundamental à vida digna, que passa pelo direito à saúde e planejamento familiar. Vedou-se a adição de restrições às pesquisas por meio interpretativo, considerando, de um lado, a necessidade de respeitar a liberdade científica, e, de outro, a suficiências das condições já enumeradas pela própria lei.

\section{O que é a vida na Colômbia?}

Da Corte Constitucional colombiana, destacamos as Sentenças C-355/06 e T388/09 sobre o aborto, bem como nas Sentenças C-239/97 e T-970/14 sobre eutanásia.

A Sentença C-355/06 trata de uma ação pública de inconstitucionalidade contra a Lei n. 890 de 2004, artigo 14, que aumentou a pena para delito de aborto. A vida humana é um problema abordado com várias respostas, como a genética, a médica, a religiosa e a moral. O legislador colombiano decidiu adotar medidas de caráter penal para proteger a vida em gestação. A princípio, isso não é uma norma desproporcional. É preciso ponderar os valores constitucionais em jogo, tais como a proteção da vida do nascituro e os direitos fundamentais da mulher grávida. No caso, decidiu-se pela prevalência da dignidade da mulher em não ser instrumentalizada como mero receptáculo da vida do novo ser, que a afetará em todos os sentidos, especialmente em caso de incesto ou de práticas contra a vontade da mulher, da violência física.

A Sentença C-239/97, por sua vez, resultou da ação pública de inconstitucionalidade, proposta pelo cidadão José Euripedes Parra contra o art. 326 do Código Penal, que prevê a figura do homicídio piedoso, sob o fundamento da inviolabilidade da vida, da não discriminação, do dever do Estado Democrático e Social colombiano em proteger tais direitos e de que é um resquício de estados fascistas e totalitários.

A Corte destacou que o homicídio piedoso é a eutanásia. Para refletir sobre o tema, argumentou, inicialmente, que o Estado colombiano se funda na dignidade da pessoa humana, destacando que o princípio significa o livre desenvolvimento da personalidade, o respeito à autonomia e à identidade de cada um. Seu conteúdo irradia-se para todos os demais direitos fundamentais, o que significa que o direito à vida pressupõe uma vida com dignidade. Nas palavras da própria ementa do caso: 
Desde una perspectiva pluralista no puede afirmarse el deber absoluto de vivir. Quien vive como obligatoria una conducta, en función de sus creencias religiosas o morales, no puede pretender que ella se haga coercitivamente exigible a todos; sólo que a él se le permita vivir su vida moral plena y actuar en función de ella sin interferencias. Además, si el respeto a la dignidad humana, irradia el ordenamiento, es claro que la vida no puede verse simplemente como algo sagrado, hasta el punto de desconocer la situación real en la que se encuentra el individuo y su posición frente el valor de la vida para sí. En palabras de esta Corte: el derecho a la vida no puede reducirse a la mera subsistencia, sino que implica el vivir adecuadamente en condiciones de dignidad.

Em outras palavras, e em passagem ainda mais clara, a Corte destacou a existência de duas posições: "1) La que asume la vida como algo sagrado y 2) aquella que estima que es un bien valioso pero no sagrado, pues las creencias religiosas o las convicciones metafísicas que fundamentan la sacralización son apenas una entre diversas opciones." Entendeu que, sob a vigência da Constituição colombiana de 1991, é preciso decidir a questão de forma secular e pluralista.

Dessa forma, a vida como valor constitucional impõe limites à proteção estatal, como o respeito à autonomia do paciente e ao livre consentimento informado sobre o tratamento. Por essa razão, a Corte decidiu que (i) uma pessoa que padeça de enfermidade terminal que cause sofrimento e (ii) que manifeste sua vontade de provocar sua morte (iii) deverá praticar-se algum procedimento médico, realizado por profissional de saúde para garantir o seu direito de morrer dignamente. Entendeu que existe um direito à morte digna do paciente nessas condições que forneça o seu consentimento e um dever do médico de realizar tal procedimento. Por fim, exortou o Congresso a legislar sobre o tema para especificar as pessoas e condições em que o "homicídio piedoso" pode ser realizado.

Na Sentença T-388/09 (aborto), a Corte Constitucional Colombiana autorizou a realização do aborto em caso de má formação do feto, quando decorrente de estupro em respeito aos direitos sexuais e reprodutivos das mulheres e do pluralismo do Estado Social de Direito, que pressupõe a promoção expressa da diversidade, da liberdade religiosa, de consciência, de expressão, vedando inclusive a objeção de consciência por parte das autoridades judiciais (C-355). Na mesma linha, exigiu-se das autoridades médicas responsáveis por realizar a interrupção a justificação séria do médico que se recuse. 
Atribuiu-se a obrigatoriedade da entidade prestadora de saúde realizar tal interrupção para não trazer prejuízos à vida e saúde da mulher, vedando-se inclusive que tais entidades exijam uma autorização judicial para a interrupção da gravidez.

A Sentença T-970/14 tratou da ação de tutela proposta por Sra. Julia contra a Commeva EPS, pleiteando o direito de morrer dignamente. Na Clínica Vida, foi diagnosticado e dado início a um tratamento, referente a um câncer de colo. Ao longo dos meses, o câncer progrediu e a paciente solicitou a eutanásia ao médico por padecer de insuportáveis dores, incompatíveis com um conceito de "vida digna". Embora a Sra. Julia tenha falecido no curso do processo, a Corte entendeu que não havia motivos para deixar de se manifestar sobre a questão de fundo. Considerou a morte digna um direito subjetivo fundamental do indivíduo, reiterando a jurisprudência do caso C-239/97.

Destaque-se que a sentença previu alguns parâmetros para tal exercício, tais como (i) paciente padeça de enfermidade que produza dores intensas; (ii) consentimento livre, informado e inequívoco; (iii) prevalência da autonomia do paciente, com celeridade, oportunidade e imparcialidade. Por fim, determinou que o Ministério da Saúde em 30 dias emita uma diretriz para que os hospitais e clinicas prestem tal serviço, bem como exortou o Congresso a legislar a respeito.

Apresentadas as decisões do Brasil e da Colômbia, destacando a ênfase que atribuem à dignidade da pessoa humana e à liberdade da mulher, passa-se à jurisprudência das demais Cortes. Nessa segunda parte, ficam evidentes as précompreensões biocêntricas/geocêntricas/interculturais de um estado plurinacional para descrever o direito à vida, especialmente a partir da noção de "bem viver" (buen vivir, suma qmaña ou sumak kawsay). Essa cosmovisão das populações originárias da América Latina pode ser encontrada nas Cortes do Equador (Caso 0072-14-CN ou caso Waorani sobre genocídio) e da Bolívia (Sentença Constitucional Plurinacional n. 0206/2014 sobre o aborto)

\section{O que é a vida no Equador?}

No caso 0072-14-CN, o chamado caso Waorani, a Corte Constitucional foi consultada sobre interpretação intercultural do art. 441 do Código Penal, relativo ao crime de genocídio que tem o importante objetivo de proteger o direito fundamental à vida, no âmbito de um processo penal contra membros da nacionalidade Waorani. No caso, ocorreu da morte anciãos Waorani na Comunidade de Yarentaro por um grupo denominado Taromenane ou povos indígenas em isolamento. 
Em reação a morte de seus anciãos, os Waorani realizaram uma incursão na mata, matando membros da Comunidade Yarentaro e, depois, retornando a sua comunidade. 0 Pleno da Corte Constitucional entendeu que o art. 441 merece uma interpretação intercultural, determinando inclusive a realização de perícias antropológicas, para se evitar a vulneração de direitos constitucionais, chamando atenção para o fato dos Waorani serem um povo de recente contato.

Desse modo, lendo a Convenção sobre a prevenção e sanção do crime de genocídio dentro de uma perspectiva intercultural, a Corte determinou o retorno do caso concreto a outra instância e que fosse tomada a decisão a partir de uma série de parâmetros nesse sentido. A vida, portanto, deve ser protegida dentro de como ela é percebida a partir de certos valores comunitários.

\section{O que é a vida na Bolívia?}

Na Sentença Constitucional Plurinacional n. 0206/2014, proferida em uma ação de inconstitucionalidade abstrata proposta pela deputada Patricia Mansila Martinez, pleiteando a inconstitucionalidade de alguns dispositivos do Código Penal. $\mathrm{O}$ acórdão proferido é particularmente interessante pelos fundamentos que declarou a constitucionalidade do art. 263 do CP que tipifica o aborto, permitindo-o em algumas exceções, como, por exemplo, com o consentimento da mulher em caso de perigo de vida para mãe ou tiver resultado de um crime. Ainda assim, procurou contextualizar a constitucionalidade da tipificação do aborto e declarar a inconstitucionalidade de procedimentos que dificultassem a sua realização do aborto legal, como uma autorização judicial, o início da ação penal ou a tipificação da prática reiterada de abortos que foi tipificada também, mas o TCP excluiu dessa os realizados por profissionais dentro das hipóteses autorizadas.

O caso é interessante por dois motivos principais. Em primeiro lugar, pela ênfase que atribui à liberdade da mulher a partir de uma ótica descolonizadora e "despatriarcalizadora" a ser perseguida pelo Estado plurinacional boliviano, remontando inclusive a prática do aborto como resistência ao colonizador para que os filhos não fossem escravizados.

Em segundo lugar, pela definição que traz do direito à vida sob o ponto de vista de uma cosmologia indígena na qual a vida é concebida como um ciclo, relacionado à pacha mama. Essa "ciclicidade" da vida e da comunidade humana não é isolada do cosmos, da pacha. A vida é criação da própria pacha a partir de energias profundas e opostas, 
tangíveis e não tangíveis. Decorrentes da energia e movimento, a profundidade é denominada de "manqha pacha", que complementa e se perfaz na realidade no micro cosmo (aka pacha) sem início, nem fim. Em passagem encantadora do voto, a vida é definida assim:

Por tanto, la "vida" desde la concepción de las naciones y pueblos indígenas es un "estar" en diferentes espacios del cosmos o pacha, cumpliendo la ley cósmica de la ciclicidad, es la eterna "transición" en diferentes momentos y espacios cósmicos, y como el ser humano, transita a diferentes espacios (cuatro espacios), la vida se concibe de manera holística; en el que todos los "seres vivos" son parte del cosmos, y como tales llegan a constituirse en la comunidad cósmica (sentido propio), en cualquiera de los espacios: aka pacha, manqha pacha, alax pacha y hanan pacha.

As concepções tradicionais denominam filho ou filha, em aymara, de wawa. Ser wawa abarca as expressões dos ciclos de fertilidade e crescimento, inclusive das plantas e animais. La wawa e a mulher são parte da comunidade. Em suma, wawa é a transição para outros espaços, a continuidade da constituição da terra, a energia em um eterno espiral que se transmite na transição natural ao outro. Nas culturas ancestrais, wawa é digna de proteção e cuidado.

Nessa linha, demonstra-se que, em diversas etnias, o aborto (sullu) é como um acidente ou fato natural na Pachamama. A mãe natureza possui efeitos abortivos, por exemplo, em fenômenos naturais, como o vento, chuva e solo e também no aborto. Considera a vida como energia e movimento. Não reconhece, ainda assim, um direito absoluto ao aborto. Admite a legitimidade da proteção penal nas últimas etapas da gestação e a legitimidade da criminalização do infanticídio desde que inferior ao homicídio. Exortou, ao fim, o Legislativo e o Executivo para desenvolver políticas públicas que diminuíssem os abortos clandestinos, desenvolvessem programas de apoio social a favor das mães solteiras, políticas de educação da reprodução sexual, programas de apoio aos pais de filhos com enfermidades congênitas e políticas de adoção.

Deve-se enfatizar, ainda assim, que um aborto incondicional em qualquer etapa da gestação não é compatível com a Lei Fundamental. Apenas em certos casos, como os de risco de morte, mediante autorização judicial e com consentimento da mulher, sua realização seria possível, sem violar a cosmovisão indígena. A autorização para sua realização, no marco da interculturalidade e do pluralismo jurídico, apoia-se na compreensão de que a vida é concebida como energia vital, movimento do cosmos, 
criação da pachamama o que implica perpetuidade constante "sem início ou sem fim", razão pela qual se compreende a vida em sentido amplo.

\section{Apontamentos finais}

Em desfecho, destaca-se a conexão entre a primeira parte do texto e a segunda. Na primeira, são abordadas as diferenças e semelhanças entre o neoconstitucionalismo e o novo constitucionalismo latino-americano com um tom crítico-reflexivo. Na segunda, adota-se uma perspectiva mais descritiva da jurisprudência das Cortes Constitucionais sobre o direito fundamental à vida. A opção justifica-se por se atribuir nas controvérsias desse direito a possibilidade de ampliar a compreensão sobre os dois elementos centrais de ambos os movimentos: a dignidade da pessoa humana e o bem viver. Colocar lado a lado essa jurisprudência fornece elementos de instituições jurídicas qualificadas dotadas de relevância ímpar em registrar/construir o sentindo e alcance desses princípios fundamentais.

A reflexão crítica sem a descrição da realidade é vazia. A descrição da realidade sem uma reflexão crítica é sem propósito. Apresenta-se, a seguir, por isso, um compêndio das principais ideias desenvolvidas, de modo a evidenciar a conexão entre as duas partes. Perceba-se que esse breve exercício de comparação jurídica entre a jurisprudência das Cortes Constitucionais do Brasil, Colômbia, Equador e Bolívia evidencia justamente tais diferenças e semelhanças entre as duas primeiras e as duas últimas e, em última análise, entre o neoconstitucionalismo e o novo constitucionalismo latino-americano. Vejamos:

1. O neoconstitucionalismo possui como marcos as Constituições europeias do pós-guerra, o pós-positivismo, a força normativa da Constituição e a expansão da jurisdição constitucional. Diferencia-se do novo constitucionalismo latino-americano que tem como marcos as Constituições, em especial da década de 1990 e dos anos 2000, apoiadas em propostas descolonizadoras de movimentos sociais, representadas teoricamente em reflexões como aquelas presentes na "epistemologia do sul" e na "filosofia da libertação". O principal destaque é a constitucionalização de direitos das populações originárias e/ou indígenas por meio da implementação de um modelo de Estado plurinacional.

Revista Publicum

Rio de Janeiro, Número 2, 2016, p. 222-244.

http://www.e-publicacoes.uerj.br/index.php/publicum

DOI: 10.12957/publicum.2016.23684 
2. As Cortes do Brasil e da Colômbia possuem forte influência do neoconstitucionalismo, manifestada em sua jurisprudência no forte apelo à dignidade da pessoa humana como princípio fundamental interpretativo do direito à vida. As Cortes do Equador e da Bolívia, por sua vez, inserem-se mais fortemente no novo constitucionalismo latino-americano, cuja influência se faz perceber no emprego de conceitos da população originária, como bem viver, pachamma, sumak kawsay, entre outros.

3. O debate sobre direito à vida, na jurisprudência dessas Cortes, deixa evidente a diferença entre os dois movimentos teóricos e seus conceitos basilares: o neoconstitucionalismo e a dignidade da pessoa humana no Brasil e Colômbia de um lado e, de outro, o novo constitucionalismo latino-americano e bem viver, sumak kawsay e pachamama no Equador e na Bolívia. A descrição dos casos da jurisprudência deixa entrever contraste entre as diferentes teorias subjacentes e evidencia dos processos de tomada de decisão.

4. No caso específico do direito à vida, as Cortes do Brasil e da Colômbia compreendem seu conteúdo a partir do intervalo entre o nascimento (ou origem) e a morte a ser fruída com dignidade. A vida protegida enquanto direito fundamental humano, colocado como epicentro do ordenamento jurídico. O direito à vida, nas Cortes Constitucionais do Equador e Bolívia, por sua vez, revela-se como uma permanente criação da Pachamama. A vida é compreendida como uma criação perpétua, sem início ou sem fim, cuja origem é uma energia que se desdobrará em ciclos dotados de constantes transições. A vida humana não se encontra descolada do meio ambiente no sentido geológico ou biológico, de modo que o bem viver relaciona-se a harmonia com a natureza e com o cosmos.

A diferença entre os dois movimentos nas quatro Cortes indica as nuances de grau maior ou menor entre o neoconstitucionalismo e o novo constitucionalismo latinoamericano. Não se deve exacerbar a ponto de tornar ambos os movimentos inconciliáveis ou rivais, embora, de fato, possuam marcos diferentes. É claro que a dignidade da pessoa 
humana possui um apelo antropocêntrico, enquanto o bem viver uma pegada mais biocêntrica, mas isso não significa, por exemplo, que a dignidade humana, mesmo no mínimo existencial, prescinda de um componente ecológico ${ }^{37}$. O meio ambiente, mesmo no marco do neoconstitucionalismo, relaciona-se à qualidade de vida. Sejam quais forem as pré-compreensões culturais adotadas, por isso, é certo que nenhuma Corte Constitucional referida reduziu o direito à vida à mera proteção de bens que nascem com o trabalho obstetra e termina com o do coveiro, o enterro. A vida é muito mais. O direito à vida envolve os anseios por uma vida digna, com qualidade e bem vivida.

\section{Referências Bibliográficas}

BARCELOS, Ana Paula. Ponderação, racionalidade e atividade jurisdicional. Rio de Janeiro: Renovar, 2006.

BARROSO, Luís Roberto. A dignidade humana no direito constitucional contemporâneo: a construção de um conceito jurídico à luz da jurisprudência mundial. Belo Horizonte: Editora Fórum, 2013.

Curso de Direito Constitucional Contemporâneo. Rio de Janeiro: Saraiva, 2009.

. Interpretação e Aplicação da Constituição. 7ạ. São Paulo: Saraiva, 2010.

- Neoconstitucionalismo e a constitucionalização do Direito (O triunfo tardio do direito constitucional no Brasil). In: SOUZA NETO, Cláudio Pereira de; SARMENTO, Daniel (orgs.). A Constitucionalização do Direito. Fundamentos Teóricos e Aplicações Específicas. Rio de Janeiro: Lumen Juris, 2007.

BELLO, Enzo. Política, cidadania e direitos sociais: um contraponto entre os modelos clássicos e a trajetória da América Latina. Dissertação de Mestrado pela PUC-RJ, 2007

A cidadania na luta política dos movimentos sociais urbanos. Caxias do Sul: Educs, 2013.

BICKEL, Alexander. The Least Dangerous Branch: the Supreme Court at the Bar of Politics. Bobbs-Merrill, 1962.

\footnotetext{
37 SARMENTO, Daniel. Dignidade da Pessoa Humana na Ordem Constitucional Brasileira: conteúdo, trajetórias e metodologia. Rio de Janeiro: Tese de Titularidade de Direito Constitucional da UERJ, 2015, p233: "Entendo, por outro lado, que o mínimo existencial, além da sua faceta social, possui também um componente ecológico, que envolve a garantia de condições ambientais sem as quais não há vida digna. Isto porque, independentemente do debate sobre a existência de possíveis sujeitos não humanos dos direitos fundamentais e da própria dignidade - como os animais ou a Terra (a Pachamama do constitucionalismo da Bolívia e do Equador, ou a Gaia dos ambientalistas da deep Ecology) -, é certo que a deterioração do meio ambiente pode gerar gravíssimos impactos sobre a qualidade de vida das pessoas, das presentes e futuras gerações, chegando às vezes ao ponto de comprometer o seu direito à vida digna"
} 
CARBONELL, Miguel. El neoconstitucionalismo en su laberinto. In: CARBONELL, Miguel.(Org.) Teoría Del neoconstitucionalismo. Editorial trotta, instituti de investigaciones jurídicas UNAM, sem data.

Prólogo: Nuevos tiempos para el constitucionalismo. In: Neoconstitucionalismo(s) Madrid: Editorial Trota, 2003.

CONSTANTINESCO, Leontin-Jean. Tratado de direito comparado: introdução ao direito comparado. Rio de Janeiro, 1998.

DALMAU, Rubens Martinez. ¿Se pude hablar de un nuevo constitucionalismo latinoamericano como corriente doctrinal sistematizada? Trabalho apresentado no Congresso Mundial de Direito constitucional, 2010. Disponível em: <http://www.juridicas.unam.mx/wccl/ponencias/13/245.pdf>

. Asembleas constituintes e novo constitucionalismo em América Latina. Tempo exterior: Revista de análise e estudos internacionais. N. 17, 2008. Disponível em: <http://www.igadi.org/te/pdf/te_se17/te29_17_005_ruben_martinez_dalmau.pdf>

. PASTOR, Roberto Viciano. ¿Ganar o perder? La propuesta de reforma constitucional em Venezuela y el referendo de 2007. Disponível em: <http://www.ceps.es/webantigua/investigacion/informes/ptalsxxi/1-julio2008.pdf>

DIMOULIS, Dimitri. Neoconstitucionalismo e moralismo jurídico. In: SARMENTO, Daniel (Org.). Filosofia e teoria constitucional contemporânea. Rio de Janeiro: Lumen Juris, 2009.

DUSSEL, Enrique. Filosofía de la liberación. p. 54-91. Disponível em:<http://www.olimon.org/uan/liberacion.pdf>

Meditações anti-cartesianas sobre a origem do anti-discurso filosófico da modernidade. In: SANTOS, Boaventura de Sousa; MENESES, Maria Paula; Epistemologias do sul. 2a. ed. Coimbra: Almedina, 2010.

DWORKIN, Ronald. No domínio da vida. São Paulo Martins Fontes, 2009.

.O que é uma vida boa?. Trad. Emilio Peluso Neder Meyer e Alonso Reis Freire Rev. direito GV [online]. 2011, vol.7, n.2, pp. 607-616.

FAVOREU, Louis. La constitutionnalisation du droit. In: Jean-Bernard Auby et al., L'unité du droit. Paris: Economica, 1996.

FERNANDES, Bernardo Gonçalves. A teoria da Constituição à luz dos movimentos do constitucionalismo (moderno), do neoconstitucionalismo (contemporâneo), do transconstitucionalismo e do constitucionalismo (latino-americano) plurinacional. In: MORAIS, José Luis Bolzan de; BARROS, Flaviane de Magalhães Barros. Novo Constitucionalismo latino-americano. Belo Horizonte: Arraes Editores, 2014.

GARGARELLA, Roberto. Latin american constitutionalism: the engine room of Constitution - 1808-2010. Oxford University Press, 2013. 
HIRSCHL, Ran. From comparative constitutional law to comparative constitutional Studies. International Journal Of Constitutional Law. Vol. 11, 2013.

JACKSON, Vicki. Comparative constitutional law: Methodologies. In: The Oxford Handbook of Constitutional Law.Ed. Rosenfeld, Michel; SAJO, Andras. Oxord: Oxord University Press, 2013.

LEGALE, Siddharta ; CAMARGO, Margarida Maria Lacombe ; JOHANN, Rodrigo Fonseca . As audiências públicas no Supremo Tribunal Federal nos modelos Gilmar Mendes e Luiz Fux: a legitimação técnica e o papel do cientista no laboratório de precedentes. In: José Ribas Vieira, Vanice Regina Lírio do Valle e Gabriel Lima Marques. (Org.). Democracia e suas instituições. 1a ed.Rio de Janeiro: IMOS, 2014, v. 1, p. 181-211. Disponível em: <http://www.ufjf.br/siddharta_legale/files/2014/07/Margarida-Siddharta-Rodrigo-Asaudi\%C3\%AAncias-p\%C3\%BAblicas-no-STF-nos-modelos-Gilmar-e-Fux.pdf>

MARTEL, Letícia de Campos Velho. Direitos Fundamentais Indisponíveis: Limites e Padrões do Consentimento para a autolimitação do direito fundamental vida. Tese de Doutoradopela UERJ, 2010. Disponível em: <http://works.bepress.com/cgi/viewcontent.cgi?article=1006\&context=leticia_martel>

OLIVEIRA, Fabio Correa Souza de e GOMES, Camila Beatriz Sardo. O Novo Constitucionalismo Latino-americano. In: CARVALHO, Flávia Martins de e VIEIRA, José Ribas. Desafios da Constituição - Democracia e Estado no século XXI. Rio de Janeiro, UFRJ, 2011, p. 333 e ss.

PEREIRA, Jane Reis Gonçalves. Interpretação e direitos fundamentais. Rio de Janeiro: Renovar, 2006.

. Representação democrática do Judiciário: reflexões preliminares sobre os riscos e dilemas de uma ideia em ascensão. Jurispoiesis (Rio de Janeiro), v. 17, 2014.

PERJU, Vlad. Constitutional transplants, borrowing, and migrations. The Oxford Handbook of Constitutional Law. Ed. ROSENFELD, Michel; SAJO, Andras. Oxford: Oxford University Press, 2013, p. 1328-1349.

QUIJANO, Anibal. Colonialidade do poder e classificação social. In: SANTOS, Boaventura de Sousa e Meneses, Maria Paula. (Orgs.) Epistemologias do Sul. Coimbra: Almedina, 2010.

SANTOS, Boaventura de Sousa e Meneses, Maria Paula. Introdução. In: Epistemologias do Sul.Coimbra: Almedina, 2010.

SANTOS, Boaventura de Sousa. Para além do pensamento abissal: das linhas globais a uma ecologia de saberes. In: SANTOS, Boaventura de Sousa; MENESES, Maria Paula Epistemologias do sul. 2a. ed. Coimbra: Almedina, 2010.

SARMENTO, Daniel. O Neoconstitucionalismo no Brasil: Riscos e possibilidades. In: Filosofia e teoria constitucional contemporânea. Rio de Janeiro: Lumen Juris, 2009.

Os princípios constitucionais e a ponderação de bens. In: LOBO TORRES, Ricardo (Org.). Teoria dos direitos fundamentais. Rio de Janeiro: Renovar, 1999. 
. Ubiquidade constitucional: os dois lados da moeda. In: Cláudio Pereira de Souza Neto e Daniel Sarmento. A Constitucionalização do direito. Rio de Janeiro: Lumen Juris, 2007.

Dignidade da Pessoa Humana na Ordem Constitucional Brasileira: conteúdo, trajetórias e metodologia. Rio de Janeiro: Tese de Titularidade de Direito Constitucional da UERJ, 2015.

SARMENTO, Daniel; e PIOVESAN, Flávia (Coord.). Nos limites da vida: aborto, clonagem e eutanásia sob a perspectiva dos direitos humanos. Rio de Janeiro: Lumen Juris, 2007.

SILVA, José Afonso da. Um pouco de Direito Constitucional Comparado. São Paulo: Malheiros, 2009.

. Curso de Direito constitucional Positivo. São Paulo: Malheiros, 2005.

SILVA, Virgílio Afonso. A Constitucionalização do direito. São Paulo: Malheiros, 2008.

SOUSA, Adriano Corrêa. O novo constitucionalismo latino-americano: um estudo comparado entre o bem-viver e a dignidade da pessoa humana nas culturas jurídicoconstitucionais da Bolívia e do Brasil. Disponível em: < http://www.ppgdc.uff.br/index.php?option=com_content\&view=article\&id=7\&/temid= $15>$

SOUZA NETO, Cláudio Pereira de e MENDONÇA, José Vicente Santos de. Fundamentalização e fundamentalismo na interpretação do princípio constitucional da livre iniciativa. In: SOUZA NETO, Cláudio Pereira de e SARMENTO, Daniel (Orgs.). A Constitucionalização do direito. Rio de Janeiro: Lumen Juris, 2007.

O dilema constitucional contemporâneo entre o neoconstitucionalismo econômico e o constitucionalismo democrático. In: COUTINHO, Jacinto Nelson de Miranda; LIMA, Barreto. Diálogos constitucionais: Direito, Neoliberalismo e desenvolvimento em países periféricos. Rio de Janeiro: Renovar, 2006.

TUSHNET, Mark. Taking the constitution away from the Courts. Princeton: Princeton University, 2000.

UPRIMNY, Rodrigo. Las transformaciones recientes em America Latina: tendências e desafios. Trabalho apresentado no Congresso Mundial de Direito constitucional, 2010.Disponível em: <http://www.juridicas.unam.mx/wccl/ponencias/13/242.pdf>

VERGOTTINI, Giusepe. Balance y perspectivas del dereho constitucional comparado. Disponível em: <http://biblio.juridicas.unam.mx/libros/2/642/26.pdf>

VIANNA, Luiz Werneck; CARVALHO, Maria Alice Resende de. Manoel Palacios Cunha Melo; BURGOS, Marcelo Baumann. A judicialização da política e das relações sociais no Brasil. Rio de Janeiro: Revan, 1999.

WOLKMER, Antonio Carlos. Pluralismo e crítica do constitucionalismo na América Latina. Anais do IX Simpósio Nacional de Direito Constitucional da ABDConst, Curitiba, 2010. Disponivel em: <http://www.abdconst.com.br/revista3/antoniowolkmer.pdf>. Acesso em: 14 Janeiro 2012. 
WOLKMER, Antonio Carlos e FAGUNDES, Lucas Machado. Tendências contemporâneas do constitucionalismo latino-americano: Estado plurinacional e pluralismo jurídico. Pensar Revista de Ciências jurídicas v. 16, n. 2 de jul./dez., 2011.

ZAFFARONI, Eugenio Raúl. La Pachamama y el humano. Buenos Aires: Ediciones Madres de Plaza de Mayo, 2012. 